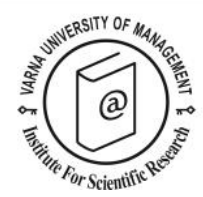

\title{
Spatial effects and institutional quality in the demand for international tourism. An application to COVID-19 impact
}

\author{
Laura López-Gómez ${ }^{1 *}$, José García-Solanes ${ }^{2}$ and Arielle Beyaert 3
}

\footnotetext{
${ }^{1}$ University of Murcia, Campus Mare Nostrum, Spain. E-mail: laura.l.g@um.es

${ }^{2}$ University of Murcia, Campus Mare Nostrum, Spain.

3 University of Murcia, Campus Mare Nostrum, Spain.
}

${ }^{*}$ Corresponding author

\begin{abstract}
This paper analyses the determinants of the tourism demand, following an approach which innovates in a) using spatial models applying a well-founded specification selection process b) exploring the effects of two types of institutions, corruption and Rule of Law, and c) assessing the spillover effects of the COVID-19 shock on the international tourism demand in Portugal and Spain. The study is conducted using a sample of 109 countries for the period 1995-2018. It shows that tourism shocks in neighbouring countries, and particularly the coronavirus pandemic, significantly affect tourism demand in the host country with the same sign as the shock itself, and that the Rule of Law of the destination country influences positively on tourists' inflow. Corruption does not seem to have significant effects on the tourist demand of the host country. From these results, we derive that national governments should provide fair and transparent legal frameworks that generate security for potential tourists. Moreover, national authorities of neighbouring countries are advised to cooperate in both promoting tourism and adopting coordinated actions against negative external shocks that hit them symmetrically, such as COVID-19.
\end{abstract}

Keywords: tourism demand, Rule of Law, spatial econometrics, geographic shocks, Covid-19

Citation: López-Gómez, L., García-Solanes, J. and Beyaert, A. (2022). Spatial effects and institutional quality in the demand for international tourism. An application to COVID-19 impact. European Journal of Tourism Research 31, 3122. 


\section{Introduction}

The literature on international tourism from the past two decades highlights the quality of institutions as a relevant determinant of tourist demand. See, for instance, Vail and Heldt (2010), Assaf and Josiassen (2012), Balli et al. (2016), and Tang (2018). On the other hand, recent studies stress the importance of including the spatial effects in inbound and domestic tourism demand (for instance, Yang and Wong 2012, and Yang and Fik 2014), and show that adding those effects to the panel data models increases forecasting accuracy (Yang and Zhang 2019, Jiao et al. 2020). However, to the best of our knowledge, no work has investigated the incidence of spatial effects combined with institutional determinants on tourism flows across large samples of countries.

To fill this gap, in this paper, we estimate an international tourism demand model, in which both elements are explicitly and simultaneously considered. On the one hand, we incorporate two indicators of institutional quality - corruption and Rule of Law - and, on the other, we address the spatial dimension by applying econometric techniques particularly designed to analyse this phenomenon, using a dataset of 109 countries for the period 1995-2018. Finally, we use our estimate to evaluate what part of the fall in tourist demand caused by the COVID-19 shock in Portugal and Spain throughout 2020 is attributable to spillover effects from the pandemic shock affecting the neighbours of these two countries. This is also an important novelty particularly relevant in the current pandemic situation.

Corruption is an institutional variable within the group of informal institutions, which are linked to the culture, habits, and behaviour of social agents. These types of institutions tend to change very gradually. The empirical literature on the impact of corruption on international tourism is not conclusive, although there is a predominance of results showing a negative sign or influences that are not significant. Tonsun and Timothy (2001) obtain that corruption deteriorates the tourist demand in Turkey due to political instability, which discourages investment in the tourist sector. Neumayer (2004) also derives a negative impact due to the insecurity that corruption creates in the country of destination. In the same line, Das and Dirienzo (2010) find that a reduction in corruption levels impacts positively on the level of tourism competitiveness because corruption deteriorates the country's image. They also obtain that the marginal gains in tourism competitiveness, from a reduction in corruption, are greater for developing countries than for developed ones. According to Propawe (2015), countries with lower corruption are more attractive for international tourists since corruption requires paying bribes that, like a tax, increase the travel costs for the tourists.

Saha and Yap (2015) find a nonlinear relationship between corruption and tourist demand, in the sense that at low levels corruption impacts positively on tourist arrivals, but the effects become negative once it exceeds a threshold. $\mathrm{Lv}$ and $\mathrm{Xu}$ (2017) also derive a nonlinear relationship between corruption and tourism demand, which is significant only at the $50^{\text {th }}$ and $75^{\text {th }}$ quantiles. Using a sample of 171 countries over 18 years, Santana-Gallego et al. (2017) obtain, from their aggregate tourism demand model, that corruption has no effect on tourist arrivals. Moreover, when they disaggregate the country-sample according to the level of development, they find that an increase in the perceived level of corruption increases the total tourist arrivals to less developed countries.

The second institutional variable we consider in this study is the Rule of Law, which belongs to the group of formal institutional indicators. These types of variables refer to judicial and legal frameworks and the implementation of social and economic policies. They change as a result of political decisions, following discontinuous or punctuated patterns. We should expect that a good rating in this indicator would generate a positive perception of the country, and a feeling of safety, which attracts the tourists. After examining six institutional variables of a set of 158 countries over eight years, Steyn and van 
Vuuren (2016) find, indeed, that the Rule of Law in the destination countries plays a relevant and positive role in the international demand for tourism services of those economies; and Balli et al. (2016) discover that the quality of formal institutions, along with civil liberty indices, are relevant in selecting tourism destinations in OECD countries. Tang (2018) obtains similar results in the case of Malaysia, and Vail and Heldt (2000) stress the crucial role of good legislation in building a long-run sustainable tourist structure.

As stressed above, in this paper we take a step further in the analysis of the influence of two prominent institutional factors on the international tourism demand by incorporating effects of spatial dependence across countries. Moreover, we also innovate in the use of spatial econometric models in the tourism literature: we apply a well-founded specification selection process that first checks the existence of spatial effects in general and, if confirmed, selects the best spatial model; this drastically reduces the risk biased estimations of the spatial effects and therefore enhance the reliability of the conclusions regarding the extent to which international tourism in a given country is affected by how international tourism behaves in neighbouring countries. Both intuition and the economic theory indicate that the geographic component must play an important role in the tourism industry and in the overall economy. Our statistical and econometric results confirm it, and our estimation of the spatial spillovers from the COVID-19 pandemic on tourist arrivals in Portugal and Spain constitutes a clear illustration of the relevance of these effects.

Our results indicate that: a) the level of corruption of the destination country does not significantly affect the number of tourist arrivals; b) the legal security and the normative quality (synthesized in the "Rule of Law") positively influence the demand for tourism towards the receiving country; c) the shocks hitting international tourism in the neighbouring countries significantly affect the tourist flows towards the analysed country with the same sign, and finally d) spatial spillovers explain 76.6 percent and 86.59 percent of the fall in tourism demand throughout 2020 in Portugal and in Spain, respectively, caused by the COVID-19 shock.

The rest of the paper is organised as follows: Section 2 briefly reviews the contributions that include spatial effects as relevant determinants in the international tourism demand. Section 3 explains the econometric methodology, and Section 4 presents and analyses the empirical results. In Section 5 we assess the spatial spillovers of COVID-19 on the international demand for tourism in Portugal and Spain in 2020. Finally, in Section 6 we offer the main conclusions and derive some prescriptions for tourism policy.

\section{Literature review on spatial effects}

Studies on tourist flows began incorporating spatial effects in 20oos. Yang and Fik (2014) instructively argue that there are two types of spatial effects in tourist flows: spillover effect and spatial heterogeneity. Spillover effect refers to influences that the tourism industry of a region or country exerts, indirectly and unintentionally, on tourist arrivals in neighbouring regions or countries. In fact, the spillover effect is related to spatial externalities - of either positive or negative sign - across regions or countries of tourist destination. Yang and Wong (2012) discuss the channels through which such effects take place in tourist flows, including influences from both demand and supply sides. Spatial heterogeneity, for its part, is the effect of tourist attraction from the infrastructure, endowments and facilities that a region or country offers its visitors. The two effects must be considered to properly model tourism demand.

There is a diversity of econometric methodologies for handling the effects of spatial dependence on tourist flows. Drakos and Kutan (2003) develop and estimate a simultaneous three-equation model to 
test the regional effects of terrorism on the tourism sectors of Greece, Israel and Turkey. They find significant contagion effects of terrorism on market shares in the region. Gooroochum and Hanlet (2005) investigate empirically the interconnectedness in long-haul visitors between the Republic of Ireland and Northern Ireland using a two-equation simultaneous model, and they find that spillovers are significant although asymmetric. De la Mata and Llano-Verduras (2012) apply the gravity equation to analyse the monetary flows of tourism between pairs of Spanish regions. Their results reveal an important border effect in favour of interregional trade flows mainly in the restaurant-industry activity. Zhang et al. (2011) apply a set of Geographical statistical tools to investigate the spatial dependence of domestic tourist distributions in 299 cities in mainland China. Their results show that the neighbouring effects are significant in both international and domestic tourism distribution, which implies that tourism development in a given city is dependent on developments in neighbouring cities. Majevska (2015) identifies and measures the inter-regional effects of spatial agglomeration in tourism in Poland using spatial association indicators and classification and taxonometrics within the cluster analysis. Using a bivariate GARCH model, Balli and Tsui (2015) discover spillover effects in the international tourist arrivals between Australia and New Zealand from seven countries, although with different relevance depending on the origin country of tourists. Balli et al. (2016) employ a multivariate ARGARCH model to estimate the impact of the spillovers from the four big clubs to other regions of New Zealand, and they find that those effects are significant.

Some authors employ vector and/or Bayesian global vector autoregressive models to quantify the crosscountry co-movements of tourism demand. For example, Cao et al. (2017) simulate the impulse responses of shocks to the Chinese economy on tourist arrivals in 24 major countries in different regions, and Assaf et al. (2018) apply this methodology to estimate and to forecast the spillover effects of international tourism across nine countries in Southeast Asia.

However, the aforementioned papers do not make use of a specific spatial econometric model, in which spatial interactions are explicitly captured via a matrix of interaction between the spatial units (i.e., between regions or countries). To the best of our knowledge, Yang and Wong (2012) inaugurated the use of such models by using a Spatial Autoregressive model (SAR) to estimate spillover effects and their determinants of inbound and domestic tourism flows to 341 cities in mainland China. In the same line, Yang and Fick (2014) use several alternative specifications of spatial econometric models to examine spillover and spatial heterogeneity effects in regional tourism growth across 342 cities in China. They conclude, on the basis of the Akaike criterion, that a model with spatial lags in the dependent variable and in the exogenous variables is the most appropriate. More recently, other authors have also used spatial components to improve forecasts of tourism flows. For instance, Yang and Zhang (2019) use spatial extensions of the time series ARIMA model, without exogenous explanatory variables, to forecast inbound tourist demand in 29 Chinese provinces. Jiao et al. (2020) also apply a local spatiotemporal autoregressive model to generate forecasts of tourist arrivals in 37 European countries with better results than with non-spatial models.

Our main task in this paper is to examine the impact of two types of institutions (formal and informal) on inbound tourism demand, jointly with other more traditional determinants of demand. Moreover, we incorporate in the analysis spatial effects to capture the geographical interactions between neighbouring countries. As a subsidiary research question, we examine how to use the resulting spatial model to evaluate the impact of the 2020 Covid pandemics on the inbound tourism demand, and we illustrate it for the case of Spain and Portugal. The characteristics of the global sample we use in this study - 109 countries with varying degrees of economic development and spatial dependence between them - advise applying the spatial-temporal modelling methodology suggested by Yang and Wong 
(2012) and Yang and Fik (2014). However, in this study we innovate carrying out a detailed data-driven econometric specification procedure to select the best model among several spatial or non-spatial alternatives, instead of adhering to a unique specification or using only the AIC criterion, to choose between the alternatives. The structure and properties of our econometric model, as well as the specification process we apply to select it, are presented in the next section.

\section{Methodology and data used}

Spatial econometrics provides suitable frameworks to deal with variables influenced by the geographical location of the phenomenon at hand, as in the case of tourism. They are particularly useful in an international context with multidirectional relationships among the variables of interest. We develop our model in two steps; in the first stage we introduce the basic model adding the terms of spatial dependence and, in the second we use the estimated spatial model to obtain spatial spillovers of pandemics in Spain and Portugal.

\subsection{Spatial model specification}

We start stating that the number of tourist arrivals depends on the per-capita GDP of the destination country and other control variables, in line, for example, with Santana-Gallego et al. (2017) and Dong et al. (2019). Moreover, we add variables related to institutional quality:

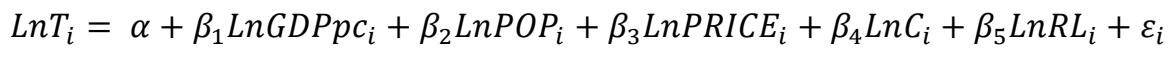

In this equation $L n T_{i}$ is the logarithm of the averaged tourist arrivals in country $i(i=1,2, \ldots, N)$, during a specific period (in our case between 1995 to 2018). $L n G D P p c_{i}$ is the logarithm of the averaged GDP per capita over the period in country $i$, as a proxy of the income level in this country. It is hypothesised that richer countries are more likely to provide higher quality public services and larger varieties of attractions for tourists. We should expect, therefore, that $L n G D P p c_{i}$ impacts positively on tourist arrivals, as in Santana-Gallego et al. (2017) and Dong et al. (2019). $L n P O P_{i}$ is the logarithm of the averaged population in country $i$, used to control for the possible economies of scale in the tourism industry as, for example, in Yap and Saha (2013) and Dong et al. (2019). It is reasonable to expect a positive impact of this variable on tourist arrivals. $L n P R I C E_{i}$ is the logarithm of the average of consumer price indices of each country $i$. Since an increase in price index of the destination country makes the stay of tourists more expensive, we should expect a negative sign for this variable. Finally, $\varepsilon_{i}$ is the error term with zero mean and limited variance.

For our purposes, we include two additional explanatory variables: corruption, measuring the quality of informal institutions, and an indicator of the legal and judicial framework, usually called Rule of Law, deemed to measure the quality of formal institutions. So, in (1), $L n R L_{i}$ and $L n C_{i}$ are the $\operatorname{logs}$ of the averaged corruption indicator and the averaged indicator of Rule of Law of country $i$, respectively. As discussed in the introduction of this paper, the level of corruption should have a negative impact on tourism flows and the Rule of Law a positive one, although we cannot a priori eliminate more ambiguous results in the case of corruption.

As an important novelty in the obtention of the spatial model, we propose to estimate the model applying a detailed specification selection procedure. This has the double advantage of a) statistically confirming the need of a spatial econometric model, and b) to let the data say which spatial model is the most appropriate one to describe the phenomenon under study. Most papers that focus on modelling international tourism demand with spatial effects opt from the beginning for a specific spatial econometrics model instead of letting the data confirm the presence and type of these effects. So, there 
is a non-negligeable risk that these papers use a misspecified model, which has effects on the reliability of their results (since misspecification at the least provoke biased estimations of the effects). In contrast, in this paper, we apply a data-based procedure argued by Florax et al. (2003) and Elhorst (2010) to ensure that the best spatial model specification, when needed, is selected. So, to fulfil a), we first apply Moran's I test statistic on the international tourism arrival data to check whether they present global spatial autocorrelation (see Tiefelsdorf and Boots 1995, for an explanation of that test statistic). Once confirmed the need of a spatial model, we then test four alternative spatial specifications: The Spatial Autoregressive Model (SAR) (see, for instance, Florax et al. 2003, equation 2), also called Spatial Lag Model (as in Figure 1 of Elhorst 2010), the Spatial Error Model (SEM) (Florax et al. 2003, equation 3 or Figure 1 of Elhorst 2010), the Spatial Durbin Model (SDM) and the Spatial Durbin Error Model (SDEM) (both in Figure 1 of Elhorst 2010). All these specifications include spatial spillovers from tourist arrivals in neighbouring countries. SAR and SEM models concentrate on spatial effects generated by the very arrival of tourists, and SDEM and SDM also incorporate the spatial effects caused by the other determinants of tourist arrivals. The last two types of models are relevant when the tourism demand is sensitive not only to endogenous but also to exogenous shocks and to what happens in the geographical environment.

The selection process of a specific spatial model consists of the following steps:

1. The first step is to choose between a SAR-type and a SEM-type model and then to decide if a Durbin extension is necessary or not. To choose between a SAR-type and a SEM-type model, we use LM-lag (Anselin, 1988) and LM-error (Burridge, 1980) tests. If the LM-lag test rejects the null and the LM-error does not reject it, we choose a SAR model. In contrast, if the LM-error test rejects the null and the LM-lag does not reject it, we select a SEM model. Finally, if both tests reject the null hypothesis, we go for a robust version of both statistics (Anselin et al., 1996). The robust LM tests are only used when both LM-lag and LM-error are significant, in which case we go to step 2. Otherwise, we can jump to step 3.

2. If the robust LM-lag rejects the null and the robust LM-error does not, we select a SAR model. If the robust LM-error rejects the null hypothesis and the robust LM-lag does not, we specify a SEM model. If both robust LM-error and robust LM-lag reject the null, we choose the model associated with the LM test that has the lowest p-value.

3. Following Elhorst (2010), we then specify and estimate a spatial Durbin model or a Spatial Durbin Error Model, depending on the results of step 1, or alternatively 2: if we have detected a SAR model, then we should estimate an SDM; on the other hand, if we previously selected a SEM model, then we should estimate an SDEM. After fitting either the SDM or the SDEM model, we use an LR test to discriminate between the pure SAR or SEM model and its Durbin extension.

4. Finally, we apply the Breusch-Pagan test to detect heteroscedasticity. If it exists, we must estimate the model with methods that correct the variances in order to ensure the reliability of the results.

In our data, as will be seen in the Results section, a spatial error model (SEM) is selected in step 2. Consequently, we go to step 3 and estimate a SDEM. After fitting this model, we use an LR test to discriminate between the specifications with and without spatially lagged independent variables. A pure SEM model would have the following specification:

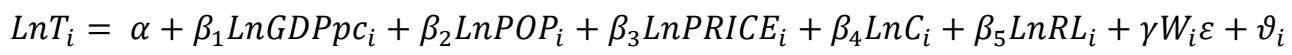

where $\varepsilon$ is the column vector which includes the error term of all countries of the sample and $W_{i}$ is the $i^{\text {th }}$ row of the spatial contiguity matrix $W$. This matrix measures the degree of contiguity or 
neighbourhood among the spatial units; in our case, the spatial units are countries, and the element $(i, j)$ of this matrix, $w_{i j}$, is equal to 1 if countries $i$ and $j$ share a common border and o otherwise, and $w_{i i}=O$ since country $i$ cannot be a neighbour of itself. The difference between model (2) and model (1) is that the latter includes the spatial matrix $W$ in the error term. The spatial error term in this model reflects the fact that shocks in the tourism demand in neighbouring countries may generate spillover effects, in the sense that a shock in any neighbour country $j$ affects the number of tourist arrivals in country $i$. On the other hand, if the null hypothesis of LR test is rejected, a Spatial Durbin Error Model (SDEM) is selected, and its specification in our case would be as follows:

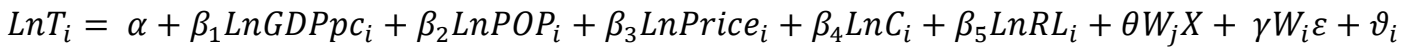

where $\mathrm{X}$ is the matrix of explanatory variables of tourism demand in all countries (i.e., its $i$-th row is composed of the row of explanatory variables of country $i$ : $X_{i}=$

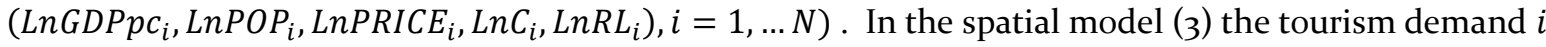
is affected by shocks that hit the tourism demand of its neighbouring countries, its own internal variables and the internal variables of its neighbouring countries.

\subsection{Data}

We use the following variables for a sample composed of 109 countries to estimate the spatial model:

1. The average number of tourists arrivals in country $i$ between 1995 and 2018. Source: World Bank.

2. Average real GDP per capita for the period 1995-2018. The data are measured in Purchasing Power Parity (PPP). Source: World Bank.

3. The average population over the period. Source: World Bank.

4. The Consumer Price Index as a proxy for the price of tourist services. Source: World Bank.

5. The average corruption indicator is derived from the International Country Risk Guide (ICRG) developed by the PSR Group. It is based on expert opinions. This indicator ranges from o to 6, where $o$ is the highest level of corruption and 6 the lowest. With this interpretation, we should expect a positive sign for the coefficient associated with the level of corruption. A positive sign would indicate that corrupt behaviours negatively affect tourist arrivals and a negative sign would denote a positive effect of corruption on tourism demand in country $i$. However, to facilitate the interpretation of the results, we have transformed the data by multiplying the indicator by -1 . Now a negative sign in the corruption coefficient indicates a decrease in tourist arrivals.

6. The average Rule of Law indicator comes from the International Country Risk Guide (ICRG) by PSR Group. The score varies between o and 6 for each country, where o is the worst institutional quality and 6 is the best possible legal and judicial framework.

3.3. Methodology to use the model in order to evaluate the spatial effects of Covid-19 on tourism towards Spain and Portugal.

In this section, we explain how to use the estimated spatial model to assess the fall in international tourism in a specific country as a result of the COVID-19 shock, and to evaluate what part of this fall is attributable to effects from the pandemic shock affecting neighbouring countries.

Again, for the sake of simplicity, we describe the procedure that we have applied particularising it to a specific spatial model: the one that has been selected by our specification procedure, which will turn to be the SEM model as will be seen in the Results section. 
Our reference equation in the description of our procedure will therefore be the estimated version of Equation (2):

$$
L n T_{i}=\hat{\beta}_{1} \operatorname{LnGDPpc}_{i}+\hat{\beta}_{2} \operatorname{LnPop}_{i}+\hat{\beta}_{3} \operatorname{LnPrice}_{i}+\hat{\beta}_{4} \operatorname{LnR}_{i}+\hat{\gamma} W_{j} \hat{\varepsilon}
$$

where $\hat{\beta}=\left(\hat{\beta}_{1}, \hat{\beta}_{2}, \hat{\beta}_{3}, \hat{\beta}_{4}\right)^{\prime}$ is the column vector of estimated coefficients of significant internal variables in country $i$ and $\hat{\gamma}$ is the spatial coefficient, and $\tilde{\varepsilon}$ is the vector of estimated shocks. We will use this estimated equation to simulate (or "predict") tourist arrivals in 2020 in country $i$, with and without the incidence of Covid-19 and to compare both simulated values in order to obtain an estimation of the impact of Covid-19 in that country, discriminating between the impact due to internal factors and the impact due to imported factors as spillover effects.

To understand the procedure, let us first be aware that, in Equation (4), from $\tilde{\varepsilon}$, the vector of estimated shocks, we only need the shocks affecting neighbouring countries of country $i$ if we want to obtain the simulated value of tourist arrivals to country i with spatial effects. Therefore, an estimation of the Covid-19 shocks suffered by the neighbours of country $i$ is necessary to compute the part of tourism arrivals decrease attributable to spatial, or imported, effects in that country. The non-spatial part of equation (4), on its side, will enable us to compute the fall in international tourist arrivals attributable to non-spatial -or internal- effects.

Let us first concentrate on how we can obtain an estimation of the shock occurring in neighbouring countries. For that purpose, let $j$ be a neighbour of country $i$ and let $\varepsilon_{j}^{20, C}$ be the Covid-19 shock of this country suffered in 2020. From now on, the superscript $C$ will refer to the Covid-19 outbreak, while the superscript $N C$ to the case where Covid-19 would not have taken place. By the same token, the superscript 20 will refer to the year 2020 while the superscript 19 to the year 2019. The shock $\varepsilon_{j}^{20, C}$ is unknown and defined as:

$$
\varepsilon_{j}^{20, C}=L n T_{j}^{20, C}-\operatorname{Ln} T_{j}^{20, N C}
$$

where $T_{j}^{20, N C}$ is the tourist arrivals to country $j$ in 2020 that would have taken place in absence of Covid19, while $T_{j}^{20, C}$ is the flow of tourist arrivals to that country under Covid-19. So, we can obtain an estimation of $\varepsilon_{j}^{20, C}, \tilde{\varepsilon}_{j}^{20, C}$, using approximations of $L n T_{j}^{20, N C}$ and of $L n T_{j}^{20, C}$ compatible with equation (4) for country $j$. The operative way is to obtain these two approximations via the systematic part of Equation (4):

$$
\begin{gathered}
\operatorname{Ln} \widehat{T}_{j}^{20, N C}=\hat{\beta}_{1} \operatorname{Ln} \widehat{G D P} p c_{j}^{20, N C}+\hat{\beta}_{2} \operatorname{Ln} \widehat{P O p}_{j}^{20, N C}+\hat{\beta}_{3} \operatorname{Ln} \widehat{\operatorname{PrlC} e_{j}^{20, N C}}+\hat{\beta}_{4} \operatorname{Ln} \widehat{R L}_{j}^{20, N C} \\
\operatorname{Ln} \widehat{T}_{j}^{20, C}=\hat{\beta}_{1} \operatorname{Ln} \widehat{G D P} p c_{j}^{20, C}+\hat{\beta}_{2} \operatorname{LnPOP_{j}^{20,C}}+\hat{\beta}_{3} \operatorname{Ln} \widehat{\operatorname{PrlC}}_{j}^{20, C}+\hat{\beta}_{4} \operatorname{Ln} \widehat{R L}_{j}^{20, C}
\end{gathered}
$$

In these equations, $L n \widehat{G D P} p c_{j}^{20, N C}$ is obtained from predictions of GDPpc for country $j$ carried out by IMF at the end of 2019, before the Covid-19 outbreak. Similarly, $\operatorname{Ln} \widehat{G D P} p c_{j}^{20, C}$ is obtained from the latest predictions of GDPpc for country $j$ published by IMF, after the COVID outbreak. By the same token, Ln $\widehat{P r l C}_{j}^{20, N C}$ is computed on the basis of the inflation prediction for country $j$ published by the International Monetary Fund for 2020 before the Covid-19 outbreak, while $\operatorname{Ln} \widehat{\operatorname{Prlc}}_{j}^{20, C}$ is computed using the latest inflation prediction carried out by IMF taken into account the existence of the pandemics. Finally, $\operatorname{Ln} \widehat{P o p}_{j}^{20, N C}=\operatorname{Ln} \widehat{P o p}_{j}^{20, C}=L n P o p_{j}^{19}$ and $L n \widehat{R L}_{j}^{20, N C}=\operatorname{Ln} \widehat{R L}_{j}^{20, C}=\operatorname{LnRL} L_{j}^{19}$ given that 
the population data, as well as the Rule of Law index, are very stable from one year to the other. Once (6) and (7) are computed using the estimated parameter of equation (4), we then obtain

$$
\tilde{\varepsilon}_{j}^{20, C}=\operatorname{Ln} \widehat{T}_{j}^{20, C}-\operatorname{Ln} \widehat{T}_{j}^{20, N C}
$$

This approximation method is used for all countries that are neighbours of country $i$. In this way, we get an estimated value for the elements of the vector $\varepsilon$ that are relevant and are needed to be plugged in equation (4) for country $i$ under the Covid-19 outbreak in 2020. These values, together with zero values assigned to elements of that vector corresponding to countries that are not neighbours of country $i$, is all we need to obtain an approximation in the fall in tourism suffered by country $i$ attributable to shocks that hit other countries. Let $\tilde{\varepsilon}^{20, C, i}$ denote the corresponding vector of Covid estimated shocks relevant for country $i$. It is made of zeros for non-neighbours of country $i$, and of values obtained by (8) for any country $j$ that is a neighbour of country $i$. The fall in tourism in country $i$ attributable in 2020 to shocks in the neighbours is therefore computed as

$$
\widetilde{S E}_{i}^{20, C}=\hat{\gamma} W_{i} \tilde{\varepsilon}^{20, C, i}
$$

The other component of the fall in tourism - attributable to internal or domestic causes - can be computed using the systematic, or traditional part, of equation (4). Let $D E_{i}^{20, C}$ denote the domestic effect of Covid-19 on international tourism in country $i$ during 2020. We estimate it in the way expressed in equation (10):

$$
\begin{aligned}
& \widetilde{D E}_{i}^{20, C}=\hat{\beta}_{1}\left(\operatorname{Ln} \widehat{G D P} p c_{i}^{20, C}-\operatorname{Ln} \widehat{G D P} p c_{i}^{20, N C}\right)+\hat{\beta}_{2}\left(\operatorname{Ln} \widehat{P O p}_{i}^{20, C}-\operatorname{Ln} \widehat{P O p}_{i}^{20, N C}\right)+\hat{\beta}_{3}\left(\operatorname{Ln} \widehat{\operatorname{PrlC}}_{i}^{20, C}\right. \\
& \left.-\operatorname{Ln} \widehat{P r l C e}_{i}^{20, N C}\right)+\hat{\beta}_{4}\left(\operatorname{Ln} \widehat{R L}_{i}^{20, C}-\operatorname{Ln} \widehat{R L}_{i}^{20, N C}\right)(10)
\end{aligned}
$$

Given our assumptions on the stability of the population variable, Pop, and the Rule of Law index, RL, from one year to the other, this computation reduces to

$$
\widetilde{D E}_{i}^{20, C}=\hat{\beta}_{1}\left(\operatorname{Ln} \widehat{G D P} p c_{i}^{20, C}-\operatorname{Ln} \widehat{G D P} p c_{i}^{20, N C}\right)+\hat{\beta}_{3}\left(\operatorname{Ln} \widehat{\operatorname{PrlC}} e_{i}^{20, C}-\operatorname{Ln} \widehat{\operatorname{PrlC}}_{i}^{20, N C}\right)
$$

The sum of the spatial-effect decrease and the domestic-effect decrease in tourism attributable to Covid19 finally provides the total estimated fall in international tourism suffered by country $i$ in 2020 due to the pandemics:

$$
\widetilde{F}_{i}^{20, C}=\widetilde{D E}_{i}^{20, C}+\widetilde{S E}_{i}^{20, C}
$$

This procedure measures therefore the total impact of Covid-19 on a country, while it takes into account both the internal and spatial, or imported, effects from neighbouring countries. The identification of these two types of effects and their relative importance in the total impact of Covid-19 in a specific country has relevant policy implications.

\section{Empirical results}

Table 1 shows the results of the Moran's I and LM tests, which provide information about the convenience of using or not a spatial model; and, if so, which type of spatial model we should specify. The table also includes the Breusch-Pagan test for heteroscedasticity 
As can be seen, Moran's I test is highly statistically significant, revealing that a spatial approach is required to modelling the tourism demand. As far as the LM tests are concerned, since both non-robust versions are statistically significant, we use the robust versions to choose the correct spatial model we should specify. The robust LM-error statistic indicates that the most appropriate model is a Spatial Error Model (SEM).

Table 1. Hypothesis testing

\begin{tabular}{lll}
\hline & Statistics & P-values \\
\hline Moran's I & $3.447^{* * *}$ & 0.000 \\
LM-lag & $8.492^{* *}$ & 0.003 \\
LM-error & $9.137^{* * *}$ & 0.002 \\
robust LM-lag & 1.693 & 0.193 \\
robust LM-error & $4.077 .^{* *}$ & 0.040 \\
Breusch-Pagan & 6.588 & 0.253 \\
\hline
\end{tabular}

${ }^{* * *}$ significance at $1 \%,{ }^{* *}$ at $5 \%,{ }^{*}$ at $10 \%$

The Breusch-Pagan test does not reject the null hypothesis, which means that it is not necessary to estimate the variance of the coefficients robustly.

The next step is to choose between pure SEM and SDEM, in which the spatial effects of independent variables are included. For this purpose, we estimate the SDEM model applying the Maximum Likelihood method. The results are presented in Table 2.

Table 2. Spatial Durbin Error Model (SDEM) estimation with Maximum Likelihood. Period: 1995-2018

\begin{tabular}{|c|c|c|}
\hline & Coefficients & P-values \\
\hline Constant & $5 \cdot 511$ & 0.380 \\
\hline$L_{n} D P p c_{i}$ & $0.936^{* * *}$ & 0.000 \\
\hline$L n P O P_{i}$ & $0.619^{* * *}$ & 0.000 \\
\hline LnPrice $_{i}$ & $-1.068^{* * *}$ & 0.002 \\
\hline$L n R L_{i}$ & $0.947^{* *}$ & 0.001 \\
\hline $\operatorname{Ln} C_{i}$ & -0.444 & 0.128 \\
\hline$\gamma$ & $0.398^{* * *}$ & 0.001 \\
\hline$W_{i} L_{n} G P p c_{i}$ & -0.037 & 0.864 \\
\hline$W_{i} \operatorname{LnPOP}_{i}$ & -0.091 & 0.394 \\
\hline$W_{i}$ LnPrice $_{i}$ & -0.918 & 0.410 \\
\hline$W_{i} \operatorname{Ln} C_{i}$ & 0.213 & 0.743 \\
\hline$W_{i} L n R L_{i}$ & 0.132 & 0.831 \\
\hline
\end{tabular}

${ }^{* * *}$ significance at $1 \%,{ }^{* *}$ at $5 \%,{ }^{*}$ at $10 \%$

As can be seen, there is no significant spillover effect corresponding to the determinants of tourism in neighbouring countries: neither the traditional determinants of tourism demand - GDP per capita, prices and population - nor the institutional indicators- corruption and the Rule of Law - of neighbouring countries affect the tourism demand of the host country. Moreover, the LR test indicates 
that we should specify the SEM model instead of the Spatial Durbin Error Model. Consequently, we estimate the SEM model applying the Maximum Likelihood method. The results are shown in Table 3.

Before analysing the results, it is convenient to clarify that the LR statistic presented in the table confirms the validity of the model with spatial effects. This statistic tests, under the null hypothesis, whether the model without spatial terms is better than a spatial model. Since the p-value associated with this LR statistic is o.ooo, the null hypothesis of a non-spatial model is strongly rejected, which ratifies the results of the Moran's I test presented in Table 1.

Table 3. Spatial Error Model (SEM) estimation with Maximum Likelihood. Period: 1995-2018

\begin{tabular}{lll}
\hline & Coefficients & P-values \\
\hline Constant & 0.611 & 0.691 \\
LnGDPpc $_{i}$ & $0.808^{* * *}$ & 0.000 \\
LnPOP $_{i}$ & $0.589^{* * *}$ & 0.000 \\
LnPrice $_{i}$ & $-0.849^{* *}$ & 0.010 \\
LnRLi $_{i}$ & $0.498^{* *}$ & 0.020 \\
LnC $_{i}$ & 0.062 & 0.753 \\
\hline $\boldsymbol{r}$ & 0.417 & 0.000 \\
\hline R-squared & 0.728 & \\
\hline Likelihood ratio test p-value & 0.002 & \\
\hline Breusch-Pagan test p-value & 0.440 & \\
\hline *** significance at $1 \%,{ }^{* *}$ at $5 \%,{ }^{*}$ at $10 \%$ & &
\end{tabular}

Table 3 shows the complete estimation with Rule of Law and Corruption. However, since Corruption and constant term are not significant, we reestimate the model removing these variables. The obtained results do not vary and they are presented in the first part of Table 4.

Table 4. Spatial Error Model (SEM) estimation with Maximum Likelihood without Corruption. Period: 1995-2018.

\begin{tabular}{lll}
\hline & Coefficients & P-values \\
\hline LnGDPpc $_{i}$ & $0.817^{* * *}$ & 0.000 \\
LnPOP $_{i}$ & $0.588^{* * *}$ & 0.000 \\
LnPrice $_{i}$ & $-0.850^{* *}$ & 0.013 \\
LnRLi $_{i}$ & $0.506^{* *}$ & 0.020 \\
\hline$\gamma$ & $0.426^{* * *}$ & 0.000 \\
\hline R-squared & 0.727 & \\
\hline Likelihood ratio test p-value & 0.001 & \\
\hline Breusch-Pagan test p-value & 0.927 & \\
\hline$* * *$ & & \\
\hline
\end{tabular}

These results allow us to highlight the following points. First, it appears that corruption is not statistically significant, while the Rule of Law indicator is confirmed as a significant factor that positively affects the number of tourist arrivals. The value of the estimated coefficient for the Rule of Law is 1.059, 
indicating that a one percent increase in the quality index of the legal and judicial framework in the host country increases the number of tourist arrivals by approximately the same percentage. These last results go in the direction of the usual findings in the literature for this specific indicator; for instance, Steyn and van Vuuren (2016) and Balli et al. (2016). So, it turns out that the security provided by a highquality legal and judicial framework is very important for potential tourists when they decide their destination country, since judicial security guarantees that everything will go well during their stay.

The fact that in our analysis corruption does not significantly affect the demand for tourism is consistent with the result of Santana-Gallego et al. (2017), according to which, although corruption impacts with a negative sign in a sample of 100 countries, the effect is not statistically significant. Our finding is also compatible with Saha and Yap (2015) and Lv and Xu (2017), in the sense that the nonlinear impact of corruption on tourism discovered by these authors implies that the sign of the impact depends on whether the corruption indicator is below or above the threshold.

It is worth stressing that our results referred to corruption derive from the estimation of an equation that, in addition to corruption, also incorporates the Rule of Law and spatial dependence across countries as important determinants of the demand for tourism. The main innovation of this work lies, precisely, in the simultaneous consideration of those three factors.

The spatial coefficient $(\gamma)$ is significant at $1 \%$, and has a positive sign, indicating that shocks on tourist arrivals in neighbouring countries affect the arrivals of tourists in the host country with the same sign. This finding confirms the intuition that what happens to my neighbour affects me. In this case, although the tourism demand and its determinants in nearby countries do not directly affect the tourism demand of the host country, there are indirect spatial effects associated with positive or negative shocks that are transmitted from neighbouring countries with the same sign.

With regard to traditional variables (GDPpc, prices and population), the results are in line with those usually obtained in the literature: the GDPpc and the size of country positively affect tourist arrivals and the price level negatively influences the tourist's inflow.

These results have important implications for the design of tourism policies. First, since measures to boost national tourism are affected by the situation in neighbouring areas, it is recommended that countries adopt coordinated tourism policies. The second implication emerges when we combine our findings with the results of Pike et al. (2006), who show that public policy gains in efficiency when it is implemented at the regional level, because closeness gives the authorities easier, quicker and deeper knowledge of the problems and opportunities presented in their regions or municipalities. In the case of tourism demand, the benefits that derive from actions at the regional level are very obvious: advantage can be taken of the dynamism of neighbouring towns or regions, in addition of detecting the problems that harm the nearby municipalities or regions more easily. Taking into account both types of results, we draw the conclusion that national governments should adopt coordinated tourism policies for their cross-border regions. This prescription could be applied, for example, to the multinational regions of the Mediterranean Basins, or to the Franco-Spanish regions on both sides of the Pyrenees. We confirm, in this way, one of the proposals of Fanfani et al. (2000) for the multi-national regions of the Western Mediterranean Sea.

\section{Spatial spillovers and Covid-19: an application to Portugal and Spain.}

In this section, we apply the estimates of our model to calibrate what part of the fall in international tourism demand in Spain and in Portugal during 2020 was due to the impact of Covid-19. We focus on 
these two countries on the basis of two considerations. First, they are important recipients of foreign visitors: 83,7 and 24,6 million tourists respectively in 2019, being second and ninth in the ranking of most visited countries of the European Union during that year. Second, the fact that they are neighbours, and that there is only a third country in the neighbourhood of both, greatly simplifies the calculations of the spatial effects.

The spatial model we obtained specifies, indeed, that the international flow of tourism to a given country depends on two main groups of factors: domestic causes corresponding to the traditional determinants of tourism and the Rule of Law, and imported effects through the shocks to tourism that affect neighbouring countries, corresponding to the spatial effects of the model. This is therefore an adequate framework to assess which part of the fall of tourism as a result of Covid-19 is attributable to internal and traditional causes, and which part obeys to the shocks caused by Covid-19 in neighbouring countries. For that purpose, we apply the procedure detailed in Section 2.3.

Our assessment will therefore be based on the estimation results of the model describing the international tourism arrivals presented in Table 4. We thus use equation (4) with the following coefficients: $\hat{\beta}_{1}=0.817, \hat{\beta}_{2}=0.588, \hat{\beta}_{3}=-0.850, \hat{\beta}_{4}=0.506$ and $\hat{\gamma}=0.426$ as the spatial coefficient. While spatial Covid effects are obtained according to equation (9) after applying equations (6) to (8), domestic effects are computed following equation (11). Finally, the sum of the spatial and domestic effects, as reflected in equation (12), will be the total estimated fall in international tourism suffered by Spain and Portugal in 2020 due to Covid-19 crisis.

The application of this methodology gives rise to the results presented in Table 5, as an illustration of our methodology for the cases of Spain and Portugal. In this table, we present the total estimated fall in tourism expressed in the number of tourists (first row) and as the percentage decrease respect to the year 2019 (second row), as well as the part of it due to the spatial effects in the number of tourists (third row) and as the percentage of the total fall (fourth row) and finally the percentage of the total fall attributable to domestic causes (fifth row).

Table 5. Predicted Spatial and Domestic pandemic effects for Portugal and Spain. Period: 2020. Unit: International tourist arrivals in number of individuals

\begin{tabular}{lll}
\hline & Portugal & Spain \\
\hline \multicolumn{1}{c}{$\tilde{F}_{i}^{20, C}$} & $-10.549 \cdot 725,2$ & $-32.456 .382,7$ \\
\hline $\begin{array}{l}\text { \% fall of International tourist arrivals } \\
\text { respect to } 2019\end{array}$ & $-34.88 \%$ & $-52.88 \%$ \\
\hline \multicolumn{1}{c}{$\widetilde{S E}_{i}^{20, C}$} & $-8.089 .529,3$ & $-28.198 .105,3$ \\
\hline \% of total fall due to spatial effects & $76.68 \%$ & $86.59 \%$ \\
\hline \% of total fall due to domestic effect & $\mathbf{2 3 . 3 2 \%}$ & $\mathbf{1 3 . 4 1 \%}$ \\
\hline
\end{tabular}

The results presented in Table 5 highlight without ambiguity the crucial relevance of spatial spillovers on international tourism demand in Portugal and Spain. They account for $76.68 \%$ of the fall of tourists' arrivals in Portugal throughout 2020, and $86.59 \%$ of the tourism-demand decline in Spain during that year as a result of the Covid-19 pandemic. To the best of our knowledge, these results provide a completely novel contribution to the tourism demand literature - and particularly to the spatial effects of the Covid-19 shock - and clearly indicate that international tourist arrivals in these countries are extremely sensitive to shocks in their neighbouring countries. It is apparent that Spain will be more 
affected than Portugal, by the fact that Spain is geographically surrounded by more neighbours than Portugal. The reported differentiation between domestic and spatial pandemic effects clearly calls for cooperation among neighbouring countries to promote and protect tourism, and to cushion the spatial spillovers caused by external negative shocks.

\section{Concluding remarks}

In this paper, we have applied spatial econometric techniques to analyse the determinants of international tourism demand using a sample of 109 countries over the period 1995-2018. Our study innovates theoretically by investigating the joint influence of two kinds of phenomena on the international tourism demand: the quality of two institutional indicators, corruption and the Rule of Law (representative of the informal and formal nature of institutions, respectively) and the geographical or spatial dimension of the issue at hand. Moreover, the spatial model that we estimate is the result of a well-founded specification selection procedure that provides more reliable results and constitutes a novelty in the tourism literature. As an extension of our analysis, we develop a procedure to quantify the effects of Covid-19 pandemics separating them between direct and spatial effects, and we illustrate the procedure with the case of two European countries. On empirical grounds, this work innovates by using a Spatial Error Model to account for the influence of external shocks, and by applying it to estimate the effects of the pandemic shock in specific countries.

We have obtained three types of results that improve the findings reported in the literature in this domain and confirm our initial hypothesis. First, the normative and judiciary framework - i.e., the Rule of Law, representative of the formal institutions - positively affects the arrival of tourists in a nonambiguous way, while corruption -representative of Informal institutions - does not have a significant effect. Second, the spatial effects are very important determinants of tourist arrivals, which indicates that what affects the arrival of tourists to neighbouring countries, in particular external shocks, is transmitted to the country understudy with the same impact sign. Third, as an application of our estimates, we find that spatial spillovers explain an important amount of the fall in international tourism demand in 2020 in Portugal (76.68\%) and Spain (86.59\%) caused by the Covid-19 shock.

We derive from these findings some policy prescriptions. A) To promote tourism, governments should provide legal frameworks that citizens perceive as fair and transparent and take steps to ensure judicial independence. These actions would generate security for potential tourists, favouring their decision to visit the country, and therefore benefiting not only the tourist sector but also the whole economy of a particular country or region. B) Tourism policies should be flexible enough to address the spatial effects coming from neighbouring countries, especially when shocks hitting neighbours are negative, as is the case with the coronavirus pandemic. C) As a result of the latter consideration, it is clear that national governments should face cooperation as a priority strategy in promoting international tourism and, most particularly, that of their cross-border regions.

\section{Appendices}

Table A-1. List of countries in the sample

Angola, Albania, Germany, Armenia, Algeria, Austria, Australia, Bahamas, Belgium, Burkina Faso, Bulgaria, Bahrain, Bolivia, Brazil, Botswana, Canada, Qatar, South Korea, Switzerland, Chile, China, Congo, Democratic Republic of Congo, Colombia, Costa Rica, Cyprus, Czech Republic, Denmark, Dominican Rep., Ecuador, Egypt, Spain, Ethiopia, Slovenia, Slovakia, United States, Estonia, Philippines, Finland, France, United Kingdom, Gambia, Greece, Guatemala, Guyana, Croatia, Haiti, Honduras, Hungary, India, Indonesia, Ireland, Iran, Iceland, Israel, Italy, Jamaica, Jordan, Japan, 
Kazakhstan, Kenya, Lebanon, Sri Lanka, Lithuania, Latvia, Luxembourg, Madagascar, Malasya, Malawi, Mali, Malta, Morroco, Mexico, Mongolia, Namibia, Niger, Nigeria, Nicaragua, the Netherlands, Norway, New Zealand, Oman, Panama, Paraguay, Peru, Papua New Guinea, Poland, Portugal, Romania, Russia, Sudan, Senegal, Singapore, El Salvador, Surinam, South Africa, Sweden, Thailand, Tanzania, Trinidad and Tobago, Tunisia, Turkey, Uganda, Ukraine, Uruguay, Venezuela, Vietnam, Zambia, Zimbabwe.

Table A-2. International tourism demand model estimation by OLS. Period: 1995-2018

\begin{tabular}{lll}
\hline & Coefficients & P-values \\
\hline Constant & 1.388 & 0.470 \\
$L n G D P p c_{i}$ & $0.829^{* * *}$ & 0.000 \\
$L n P O P_{i}$ & $0.585^{* * *}$ & 0.000 \\
nnPrice $_{i}$ & $-1.063^{* *}$ & 0.006 \\
$L n R L_{i}$ & $0.454^{* *}$ & 0.051 \\
$L n C_{i}$ & 0.249 & 0.244 \\
\hline
\end{tabular}

${ }^{* * *}$ significance at $1 \%,{ }^{* *}$ at $5 \%,{ }^{*}$ at $10 \%$

\section{References}

Assaf A G, and Josiassen A (2012) Identifying and Ranking the Determinants of Tourism Performance: Global Investigation, Journal of Travel Research, 51(4), 388-399.

Assaf A G, Li G, Song H and Tsionas M G (2018) Modeling and forecasting regional tourism demand using the Bayesian Global Vector Autoregressive (BGVAR) Model, Journal of Travel Research 26(2), 28-39.

Balli F, Balli HO and Rosmy JL (2016) The impacts of immigrants and institutions on bilateral tourism flows, Tourism Management, 52, 221-229.

Balli F and Tsui K (2015) Tourism Demand Spillovers between Australia and New Zealand, Journal of Travel research 55(6).

Cao Z, Li G, \& Song H. (2017). Modelling the interdependence of tourism demand: The global vector autoregressive approach. Annals of Tourism Research, 67, 1-13

Das J, and Dirienzo C (2010) Tourism competitiveness and corruption: A cross-country analysis, Tourism Economics, 16(3), 477-492.

Drakos K, \& Kutan A (2003). Regional effects of terrorism on tourism in three Mediterranean countries. Journal of Conflict Resolution, 47(5), 621-641

De la Mata T, and Llano-Verduras C (2012) Spatial pattern and domestic tourism: An econometric analysis using inter-regional monetary flows by type of journey. Papers in Regional Science, 91(2), 437-470.

Dong D, Xu X, Yu H and Zhao Y (2019) The Impact of Air Pollution on domestic Tourism in China: A Spatial Econometric Analysis, Sustainability 2019, 11, 4148.

Ekine S (2018) Corruption and Tourism: Evidence from democracies and non-democracies, Issues in Political Economy, Vol 27(1), 2018, 47-59

Elhorst JP (2010) Applied Spatial Econometrics: Raising the Bar, Spatial Economic Analysis, 5:1, 9-28, DOI: $10.1080 / 17421770903541772$

Fanfani R, García-Solanes J, Leonardi R and Titecat M (200o) Etude stratégique de coopération intérregionale en Méditerranée Occidentale, Rapport de la Commission Européenne. Conférence des Régions Péripheriques Maritimes d'Europe.

Florax R, Folmer H and Rey S (2003) Specification searches in spatial econometrics: the relevance of Hendry's methodology, Regional Science and Urban Economics, 33, issue 5, p. 557-579. 
Gooroochurn N, and Hanley, A (2005) Spillover effects in long-haul visitors between two regions, Regional Studies, 39(6), 727-738

Jiao X, Li G and Chen J L (2020) Forecasting international tourism demand: a local spatiotemporal model, Annals of Tourism Research, 83, July 2020, 102937.

Long W, Liu C and Song H (2019) Pooling in tourism demand forecasting. Journal of Travel Research, 58(7), 1161-1174

Lv Z and Xu T (2017) A panel data quantile regression analysis of the impact of corruption on tourism. Current Issues in Tourism, 20(6), 603-616.

Majewska J (2015) Inter-regional agglomeration effects in tourism in Poland, Tourism Geographies, 17(3) 408-436.

Marrocu E and Paci R (2013) Different tourists to different destinations: evidence from spatial interaction models, Tourism Management, 39, 71-83.

Neumayer E (2004) The impact of political violence on tourism: Dynamic cross-national estimation, Journal of Conflict Resolution, 48 (2), 259-81.

Neyapti B (2013) Modeling institutional evolution, Economic Systems, 37(1), 1-16.

Pike A, Rodríguez-Pose A and Tomaney J (2006) Local and Regional Development. Routledge, London. Poprawe M (2015) A panel data analysis of the effect of corruption on tourism, Applied Economics, Vol. 47(3), 2399-2412.

Saha S and Yap G (2015) Corruption and tourism: An empirical investigation in a non-linear framework, International Journal of Tourism Research, 17(3), 272-281.

Santana-Gallego M, Roselló J and Fourie J (2016) The effects of terrorism, crime and corruption on tourism, ERSA Working paper 595. Cape Town: Economic Research Southern Africa (ERSA).

Steyn R and Jansen van Vuuren O (2016) The relationship between quality of governance and foreign tourist numbers.

Tang CF (2018) The impacts of governance and institutions on inbound tourism demand: evidence from a dynamic panel data study, Asia Pacific Journal of Tourism Research, 23:10, 1000-1007.

Tiefelsdorf M and Boots, B. (1995) The exact distribution of Moran's I, Environment and Planning A, 27(6), 985-999.

Tosun C and Timothy D (2001) Shortcomings in planning approaches to tourism development in developing countries: The case of Turkey, International Journal of Contemporary Hospitality Management, 13(7), 352-359.

Vail D and Heldt T (2000) Institutional factors influencing the size and structure of tourism: Comparing Dalarna (Sweden) and Maine (USA), Current Issues in Tourism, 3(4), 283-324.

Yang Y and Fik T (2014) Spatial effects in regional tourism growth. Annals of Tourism Research, 46, 144162.

Yang Y and Zhang H (2019) Spatial-temporal forecasting of tourism demand. Annals of Tourism Research, 75, 106-119.

Yang Y and Wong K K F (2012) A spatial econometric approach to model spillover effects in tourism flows, Journal of Travel Research, 51(6), 768-778.

Yap G and Saha S (2013) Do political instability, terrorism and corruption have deterring effects on tourism development even in the presence of UNESCO heritage? A cross-country panel estimate, Tourism Analysis, 18, 587-599.

Zhang Y, Xu J and Zhuang P (2011) The spatial relationships of tourist distributions in Chinese cities, Tourism Geographies, 13(1), 75-90.

Zhou B, Yang B, Li H and Qu H (2016) The spillover effect of attractions: evidence from Eastern China, Tourism Economics 23(4), 731-743.

Received: 05/01/2021 
Accepted: 08/o6/2021

Coordinating editor: Martina G. Gallarza 